\title{
Considerações sobre a conversação no telejornalismo
}

\author{
Fernanda Mauricio da Silva ${ }^{1}$ \\ UFBA \\ fernandamauriciodasilva@hotmail.com
}

\begin{abstract}
Resumo: $O$ objetivo do presente artigo é verificar se e como ocorre a conversação no contexto comunicativo do telejornalismo a partir dos programas Bom Dia Brasil (Globo), Programa do Jô (Globo) e Saia Justa (GNT). Sendo assim, assumiremos o conceito de conversação a partir da etnometodologia que postula que é conversação toda troca verbal, socialmente regrada, que varia de acordo com a situação em que a troca se dá (WOLF, 1994). Acreditamos que o telejornalismo constrói-se como uma situação discursiva que cria um ambiente específico para que a conversação entre os participantes do estúdio se dê, ambiente marcado tanto pelos constrangimentos midiáticos (relacionado ao tempo de duração dos programas, à linguagem televisiva, aos interesses mercadológicos, etc) quanto pelas premissas do jornalismo (verdade e relevância, valor-notícia, interesse público, etc).
\end{abstract}

Palavras-chave: conversação; telejornalismo; vida cotidiana.

Abstract: This study seeks to determine whether, and how conversation takes place in the communicative context of television journalism, based on an analysis of the programs: "Bom Dia Brasil" (Globo), "Programa do Jô" (Globo) and "Saia Justa" (GNT). The concept of conversation adopted is that of ethnomethodology, which postulates that conversation consists of any socially-governed verbal exchange, which varies according to the situation in which it takes place (Wolf, 1994). We believe that television journalism is constructed as a discourse situation, which creates a specific environment in which the conversation among the participants of the studio takes place. This environment is characterized by both media constraints (related to the duration of the programs, television language, market interests, etc.) and the premises of journalism (truth and relevance, news value, public interest, etc.).

Key words: conversation; television journalism; everyday life.

1 Mestre pelo Programa de Pós-Graduação em Comunicação e Cultura Contemporânea da Universidade Federal da Bahia e doutoranda pelo mesmo programa. Professora das Faculdades Jorge Amado. 
Resumen: El objetivo del presente artículo es verificar si y cómo ocurre la conversación en el contexto comunicativo del periodismo televisivo a partir de los programas "Bom dia Brasil" (Globo), "Programa do Jô" y "Saia Justa" (GNT). De esta forma, asumiremos el concepto de conversación a partir de la etno-metodología, que postula que lo es todo intercambio verbal, socialmente reglado, que varíe conforme la situación en que este intercambio se produzca (Wolf, 1994). Creemos que el periodismo televisivo se construye como una situación discursiva que crea un ambiente específico para que la conversación entre los participantes del estudio se efectúe. Ese ambiente es marcado tanto por los interdictos mediáticos (relativos a la duración de los programas, el lenguaje televisivo, los intereses mercadotécnicos, etc.) como por las premisas del periodismo (verdad y relevancia, valor-noticia, interés público, etc.).

Palabras clave: conversación; periodismo televisivo; vida cotidiana.

Résumé: L'objetif de cet article est de vérifier si et comment se passe la conversation dans un contexte comunicatif du téléjournalisme à partir des programmes " Bom dia Brasil( Globo)", " Programa do Jô (Globo)" et "Saia Justa( GNT)" . Comme ça, nous assumerons le concept de conversation à partir de l' etnométhodologie qui postule comme conversation tout échange verbal, socialement réglée, qui varie d'accord la situation lorsque l'échange se fait( Wolf, 1994). Nous croyons que le téléjournalisme se construit comme une situation discursive qui crie une ambiance spécifique pour que la conversation parmi les participants du studio ait lieu, ambiance marquée autant par les contraintes médiatiques ( en rapport à la durée des programmes, au langage de la télé, aux intérêts du marché, etc )que par les prémisses du journalisme (verité et importance, valeur-nouvelle, intérêt public, etc).

Mots clés: conversation; téléjournalisme; vie quotidienne.

\section{Introdução}

No primeiro capítulo do livro Television, Raymond Williams (1997) alerta que a televisão não é tão somente uma tecnologia, mas é também, e principalmente, uma forma cultural dotada de determinados usos e práticas sociais. O autor argumenta ainda que o jornalismo é uma instituição social (Idem, p. 22) que se desenvolveu a partir do século XIX com a nova função informativa dos jornais impressos nos Estados democráticos ${ }^{2}$. É nessa perspectiva, portanto, que pensamos o telejornalismo: como uma instituição social atrelada a fatores histórico-culturais que possibilitam a criação de novas formas e funções sociais.

\footnotetext{
2 Este também é o argumento dos estudiosos do jornalismo, como Chalaby, 2003, Traquina, 2004, Schudson, 1978.
} 
Uma breve retrospectiva histórica do telejornalismo brasileiro revela que, tanto a grade de programação televisiva, quanto a configuração dos programas se modificaram ao longo do tempo a fim de se adaptar às novas possibilidades tecnológicas, à demanda da audiência, às circunstâncias político-culturais e à relação de concorrência entre as emissoras (REZENDE, 2000). Tais fatores possibilitaram agregar ao telejornalismo recursos técnicos (vídeo-tape, ao vivo, cenários, efeitos sonoros, vinhetas), estratégias mediáticas (divisão dos programas em editorias, estruturação dos blocos dos telejornais das notícias mais importantes para as mais leves, criação de novos programas) e novos conteúdos (aproximação com o campo político a partir do enfraquecimento da censura, programas temáticos, aprofundamento das notícias por meio de entrevistas e debates). Podemos pensar, portanto, que os programas jornalísticos se modificaram historicamente e utilizaram diversas estratégias para atrair a audiência e sobreviver às pressões da concorrência, a exemplo da modificação da função dos apresentadores, que inicialmente se prestavam ao papel de locutores (ao qual não era exigida a formação de jornalista) e, a partir dos anos noventa, passaram a ser jornalistas responsáveis pela leitura e interpretação das notícias (REZENDE, 2000, p. 133).

O foco do presente artigo é em uma das presentes estratégias utilizadas pelo telejornalismo: a conversação. Como fenômeno que utiliza a linguagem verbal e nãoverbal (gestos, expressões faciais, tom de voz), a conversação é uma prática social cotidiana inserida na cultura (BURKE, 1995; WOLF, 1994; BRAGA, 1994) e, portanto, sujeita a alterações provenientes das variações culturais: novas formas de relações interpessoais, influência dos meios de comunicação massivos e nãomassivos, constrangimentos políticos e econômicos (que permitem ou inibem os encontros interpessoais). Se a conversa entre os indivíduos varia em função do contexto em que ela se dá, pretendemos, no presente artigo, observar as características da conversação no contexto do telejornalismo operacionalizando os critérios estabelecidos por José Luiz Braga (1994) para análise de produtos midiáticos e levando em conta os constrangimentos impostos pelas premissas do jornalismo e pela linguagem televisiva. Selecionamos os programas Bom Dia Brasil (Globo), Programa do Jô (Globo) e Saia Justa (GNT) como corpus de análise por apresentarem usos e propósitos diversificados sobre a conversação. 


\section{A conversação como prática cotidiana}

Ao utilizarem a conversação para configurar suas estratégias de construção, os programas telejornalísticos tomam posse de práticas sociais já estabelecidas na vida cotidiana e, por isso, reconhecíveis para a audiência. Se na experiência diária os indivíduos se apropriam de regras conversacionais socialmente partilhadas para interagirem em função da situação, o mesmo ocorre nos programas televisuais. Este é o pensamento de José Luiz Braga ao afirmar que

toda sociedade dispõe de uma variedade de "dispositivos conversacionais" que são ativados segundo as circunstâncias socioculturais das interações. Quando um programa de televisão põe em cena conversações, tem que se remeter a esses dispositivos; mas ao mesmo tempo deve obedecer a direcionamentos da "linguagem televisiva" (para o ritmo, a duração, a vez de falar, os papéis desempenhados, etc). Esses dispositivos são geralmente reconhecíveis, como moldes nos quais se desenvolvem estratégias pessoais (BRAGA, 2006, p. 2).

Na vida cotidiana, as conversas variam em função da situação em que ela se dá, o que implica pensar em elementos contextuais que conformam o comportamento dos indivíduos durante a troca. Erving Goffman (2005) explica que para que a interação seja adequada, as pessoas que dela fazem parte devem partilhar um conjunto de informações umas sobre as outras a fim de saberem como proceder. O reconhecimento de tais informações serve para "definir a situação, tornando os outros capazes de reconhecer antecipadamente o que ele esperará deles e o que dele podem esperar" (GOFFMAN, 2005, p. 11). Sobre o trabalho de Goffman, Mauro Wolf (1994, p. 35) afirma que para definir uma situação, é preciso perceber “o que está acontecendo", o que significa

estabelecer los límites del comportamiento apropriado, el marco que distingue el episodio y sus contenidos de otras realidades sociales cercanas o parecidas, cualificar a los sujetos según el tipo de rol y personage que encarnan en esa ocasión (WOLF, 1994, p. 35).

Tendo identificado a situação a partir de quadros interpretativos (frames ${ }^{3}$ ), o indivíduo seleciona as melhores estratégias para representar-se a partir de sua competência cultural. A competência pode ser confrontada quando um indivíduo se percebe numa situação que nunca viveu antes, como é o caso de um morador de uma

3 Frame é um conceito criado por Goffman para designar as "instrucciones necesarias para descifrar, para dar un sentido al flujo de los acontecimientos" (Wolf, 1994, p. 40). 
pequena cidade do campo que passa a morar numa cidade grande (ou na situação inversa) e precisa aprender uma nova gramática de interação social. Assim, ele poderá tornar suas regras reconhecíveis e partilhar o novo código sem cometer "gafes".

La competencia cultural en el uso de las reglas de la conversación durante las interacciones socieales, no manifesta solamente uma competencia social adecuada de los sujetos, sino, lo que es más importante, proporciona una base de procedimiento para la organización constante de los encuentros que los sujetos tienen en su vida cotidiana (SPLIER apud Wolf, 1994, p. 188, grifo do autor).

Os indivíduos estão de tal forma familiarizados com as regras da conversação que as utilizam de forma intuitiva e é isso que confere a impressão de espontaneidade tão atribuída à conversação. Observamos que há uma operação de regras bem definidas quando estas são rompidas: quando alguém monopoliza a fala, rapidamente sentimos uma violação das regras e interpretamos tal atitude como falta de polidez e má educação. Por isso, Mauro Wolf (idem) e Braga (1994) afirmam que, apesar de parecerem espontâneas, as conversas são extremamente regradas e necessitam de competências para que a comunicação seja efetivada.

Propondo um método de análise das conversações na vida cotidiana, a Análise da Conversação ${ }^{4}$ sugere cinco critérios, a saber: o funcionamento dos turnos de fala, a cooperação entre os participantes, o mecanismo de interpelação/resposta, as seqüências que se interpõem ao sistema interpelação/resposta e as correções. Acreditamos que esses operadores são insuficientes para análise dos programas telejornalísticos uma vez que não levam em conta aspectos contextuais da televisão e estão demasiadamente focados em aparatos lingüísticos. Ao propor critérios de análise da conversação nos produtos midiáticos, Braga (1994) não se limita apenas aos dispositivos lingüísticos operacionais, mas dedica-se principalmente ao contexto que os programas buscam reproduzir. Assim, o autor definiria uma conversação

\footnotetext{
4 A Análise da Conversação (AC) é uma corrente de investigação variante da etnometodologia e da sociologia de Erving Goffman, que visa analisar tanto as interações interpessoais institucionais quanto as casuais. O objetivo é ver como a conversação funciona em diferentes ambientes (settings). Mauro Wolf (1994, p. 187) afirma que são de interesse da AC as conversas telefônicas, as rápidas interações entre colegas de trabalho num momento de ócio, a sessão terapêutica, o perguntar e responder as horas, as conferências de imprensa, as palavras sussurradas ao ouvido, ou seja, tudo que presume pelo menos uma troca de palavras entre os indivíduos - interpelação e réplica (Marcuschi, 1998). Os autores que fundaram essa corrente (por volta da década de 60) foram Harvey Sacks, Emanuel Schegloff e Gail Jefferson.
} 
televisual em termos de vez de falar; movimentos para início e fim da troca; papéis e relações entre participantes; quadro que cerca a conversação; graus de formalização e controle; objetivos e resultados; assuntos e temas e o número e possibilidade de participantes. É com base nesses operadores, que atuam de forma articulada no interior dos programas, que pretendemos verificar as conversações postas em cena pelo Bom Dia Brasil (Globo), Programa do Jô (Globo) e Saia Justa (GNT).

\section{A conversação no telejornalismo}

Programa do Jô, Saia Justa e Bom Dia Brasil são programas com natureza bastante diversa entre si: eles pertencem a subgêneros televisivos ${ }^{5}$ diferenciados (talk show, programa de debate e telejornal, respectivamente), possuem propostas diferentes sobre o papel do jornalismo ${ }^{6}$, os papéis desempenhados por seus participantes não traduzem a mesma função, as estratégias enunciativas e a temática abordada não são as mesmas, o contexto em que se inserem na grade televisiva não se assemelha. O que há de comum entre esses três programas é o uso da conversação com o propósito de atrair sua audiência, relatar os temas que fazem parte de seu repertório e construir seu próprio estilo. Por conta dessas diferenciações, a natureza da conversação encenada nos programas também irá se modificar. São essas

\footnotetext{
5 A conceituação de gêneros e subgêneros televisivos parte dos trabalhos desenvolvidos pelo grupo de pesquisa Análise de Telejornais (Programa de Pós-Graduação em Comunicação e Cultura Contemporânea - UFBA), coordenado pela professora Dra. Itania Gomes. De acordo com essa perspectiva, gêneros televisivos são estratégias de comunicabilidade (Barbero, 1997) que definem tanto os parâmetros de produção quanto o horizonte no qual os receptores devem interpretar os textos. Assim, são gêneros televisivos o telejornalismo, os programas de auditório, a ficção televisiva, os reality shows, etc. No telejornalismo, encontramos como subgêneros os telejornais, os programas de debate, documentários jornalísticos, programas temáticos, programas de entrevista, talk shows, entre outros. Sobre esse assunto, ver GOMES, Itania. A noção de gênero como estratégia de interação: o diálogo entre os cultural studies e os estudos da linguagem. In: Revista Fronteiras, São Leopoldo, Programa de PósGraduação da UNISINOS, dezembro de 2002.

${ }^{6}$ Apesar de considerarmos de extrema relevância a discussão sobre os limites do jornalismo na televisão, não é nosso propósito, neste artigo, dedicarmo-nos a uma discussão exaustiva sobre esse tema. Por ora, definimos como programas jornalísticos televisivos aqueles que estão ancorados no discurso da "representação fiel da realidade" (Duarte, 2004), a "janela para o mundo" (Jost, 2004a, 2004b). O modo como essa representação é feita (se por meio de uma única reportagem, como os documentários jornalísticos; se pela oferta "das principais notícias do Brasil e do mundo", como os telejornais; se pelo acesso a uma única fonte de informação, como os programas de entrevista; se repercutindo as principais questões da atualidade por meio da troca de opiniões entre especialistas ou pessoas comuns, como os programas de debate) não compromete a característica central dos programas que é a referencialidade aos acontecimentos importantes e interessantes da atualidade.
} 
possibilidades que, por ora, pretendemos apontar com análises de cada um dos programas.

\section{1 - Bom Dia Brasil: dois locais para conversar}

Sabendo do hábito de certos leitores acessarem as informações dos jornais impressos pela manhã a fim de obter uma perspectiva mais aprofundada das notícias da véspera7, o telejornal matinal da Rede Globo, Bom Dia Brasil (BDB), propõe o mesmo pacto para a audiência: fazer um balanço dos fatos mais importantes do dia anterior a fim de preparar o telespectador para o que pode ocorrer naquele dia. Por ser o primeiro telejornal do dia da emissora, o BDB promete promover uma reflexão dos principais assuntos abordados pelos telejornais, uma vez que, pelo seu horário de exibição (das sete e dez às oito horas), pouca coisa aconteceu. Para cumprir essa promessa, o BDB apresenta as matérias num período mais longo do que o fazem os demais telejornais (enquanto o tempo médio de duração de uma matéria é de dois minutos, no BDB essas matérias podem chegar a cinco minutos) e trazem jornalistas especializados para comentá-las: Mirim Leitão comenta preferencialmente economia, Alexandre Garcia fala sobre política e Tadeu Schmidt é o comentarista de esportes. Toda a conversação do BDB se passa entre esses participantes e os apresentadores do programa Renato Machado e Renata Vasconcelos - apresentadores oficiais, no Rio de Janeiro - Mariana Godoy e Cláudia Bomtempo, apresentadores de São Paulo e Brasília, respectivamente.

Para receber esses participantes, o cenário do programa se estrutura em dois ambientes. O primeiro contém uma bancada onde os apresentadores Renato Machado e Renata Vasconcellos se posicionam para introduzir o telejornal e chamar as notícias que serão abordadas na edição do dia. Esse é o ambiente da bancada, que carrega consigo a credibilidade e autoridade do jornalismo de ser a instituição social responsável pela "produção e oferta de notícias, de informação sobre a atualidade, isto é, sobre estados temporalmente determinados no mundo" (GOMES, 2003, p.15).

O outro ambiente do BDB assemelha-se a uma sala de visitas. Pode ser da casa ou de um salão de espera, mas as poltronas, a mesa de centro e o telão ao fundo,

\footnotetext{
7 Há uma crença de que os jornais impressos tomam para si um papel social de aprofundar mais as notícias, posto que os telejornais, em função da brevidade do tempo oferecido pela televisão, apenas fornecem uma versão superficial dos fatos.
} 
que mostra os estúdios do $\mathrm{BDB}$ nas outras capitais e também as matérias, revelam o ambiente confortável que uma conversa deve ter. A sala de visitas é o lugar por excelência para assegurar o espaço de conversação nos apartamentos modernos (TARDE, 1992, p. 118) e é este ambiente que o BDB propõe.

Neste cenário, os participantes têm dois tipos de conversa: uma esclarecedora, na qual os jornalistas especialistas possuem o papel fundamental de aprofundar as informações relatadas, e outra mais leve e descontraída, restrita a breves comentários feitos pelos apresentadores. Como exemplo desses dois tipos de conversa, encontramos na edição do dia 5/06/o6 os seguintes diálogos:

Exemplo 1: após a exibição de uma matéria sobre o julgamento de Suzane Von Richtofen e dos irmãos Daniel e Christian Cravinhos.

Mariana Godoy:

(no estúdio em São Paulo, por meio de um telão)

\section{Renato Machado:} (na poltrona)

Cláudia Bomtempo: (em Brasília, por meio de um telão)

Alexandre Garcia: (em Brasília, ao lado de Cláudia)
O irmão de Suzane, Andréas, vai participar do julgamento e ele foi convocado, Renato, como testemunha tanto pela defesa, quanto pela acusação.

É, e a Suzane foi presa também porque foi considerada uma ameaça para o irmão. Vamos agora para o novo estúdio de Brasília onde está a repórter Cláudia Bomtempo. Cláudia, a Justiça proibiu a transmissão ao vivo do julgamento?

Isso mesmo Renato. $\mathrm{O}$ pedido feito pela Associação dos Advogados Criminalistas de São Paulo foi negado pelo Ministro do Superior Tribunal de Justiça, Milton Naves. Só vão ser permitidas imagens do início do julgamento e do momento em que a sentença for anunciada. Alexandre Garcia, não deixa de ser um julgamento público.

É, portas abertas, mas sem TV. Enfim, o país parece mais interessado na Copa. No limiar desse julgamento, há uma desconfiança de que alguns sejam mais iguais que outros, embora a teoria constitucional seja de que "todos são iguais perante a lei”. Alguns eleitos, por exemplo, não são iguais aos seus eleitores porque, afinal, têm foro especial, embora sendo "sanguessugas". Depois de tantas absolvições de mensaleiros confessos, a decepção se tornou grande em relação aos julgamentos políticos na Câmara. Bem, resta a confiança na Polícia Federal e no Ministério Púbico. E quanto ao Judiciário, neste caso, julga-se também um pouco se os ritos da lei e da justiça são justos. Renato.

Pode-se notar, neste exemplo, uma hierarquização dos papéis discursivos dos mediadores na condução do programa. Segundo Sonia Livingstone e Peter Lunt (1994), os apresentadores de programas televisivos (no caso dos autores, talk shows) desempenham performances cênicas que reproduzem uma atividade da vida cotidiana 
no contexto midiático: a sala de aula, o sermão, o discurso político e o ato de contar histórias. "Cada uma dessas formas constrói um relacionamento diferente entre falante, ouvinte e argumento" (ibidem, p. 138, tradução nossa) e, portanto, cada uma delas traz um tipo de conversação. A sala de aula evidencia alguém que ensina a outrém; o sermão incita a reflexão sobre os temas a partir da contemplação; o discurso político mostra a voz incontestável de uma fonte oficial; o ato de contar histórias remete à troca de experiências das pessoas comuns e, por isso, quem as conta deve ser interessante e relevante.

Renato Machado, Mariana Godoy e Cláudia Bomtempo encenam um tipo de conversação na qual eles trocam informações sobre os assuntos que dominam em função da proximidade geográfica com o local do acontecimento narrado. Deste modo, Mariana Godoy possui autoridade para falar sobre o julgamento pois ele se passará em São Paulo. Percebemos que é uma conversa regulada, com falas e tempos bem definidos e que as rápidas interpelações entre os apresentadores tem uma função jornalística de coordenar a emissão do programa, funcionando como uma espécie de "deixa". Essa conversa traz um tom de informalidade, como se os participantes estivessem acrescentando alguma coisa ao que os outros dizem. Por outro lado, os apresentadores também se posicionam como "alguém que quer saber algo" e para isso recorrem a uma autoridade maior que a deles dentro do programa: Alexandre Garcia, que extrapola o assunto abordado e o leva para uma reflexão sobre a política e o Poder Judiciário no país por meio de um sermão. Jornalisticamente, essa autoridade é construída com base em sua trajetória dentro do campo e no reconhecimento que os telespectadores já possuem sobre seus comentários num segmento específico do jornalismo. Nesse caso, a performance dos apresentadores é da sala de aula pois eles visam instruir a audiência sobre assuntos que acreditam ser de interesse público, muito diferente do outro modelo de conversação do programa.

\footnotetext{
8 Jargão jornalístico que conota as palavras finais de alguém para que o diretor de TV mude a câmera e os outros personagens envolvidos saibam qual será sua vez de falar.
} 
Exemplo 2: após exibição de várias reportagens sobre a Alemanha e as seleções que disputariam a Copa do Mundo.

Tadeu Schmidt:

(no telão, ao vivo, da Alemanha).

\section{Renata Vasconcellos:} (no estúdio, nas poltronas)

Tadeu Schmidt:

Renato Machado:

(no estúdio, nas poltronas)
O que parece que não vai mudar por aqui é o frio, viu gente, porque quando começou o Bom Dia, estava um pouquinho mais de dez graus, agora está um pouquinho menos de dez graus. Mas com certeza teremos dias quentíssimos, se Deus quiser, dias muito felizes aqui em Königstein. Estava com saudade de vocês, viu, Renato, Renata...

(Sobreposição das falas)

A gente também, Tadeu.

Estava aqui olhando o novo cenário nosso. É bonito, hein?!

É, pois é. Mas a gente vai ficar se vendo, Tadeu, todo dia.

Aqui, temos uma conversa entre amigos que já não se vêem há algum tempo e, ao se encontrar, precisam matar a saudade. Como o assunto é leve (esporte), muitos risos marcam esse momento final do programa. Em certos casos, como se pôde verificar, há uma sobreposição de falas entre os participantes, o que caracterizaria uma conversação cotidiana e fugiria do rigor de qualidade dos telejornais nos quais cada fala tem seu tempo determinado. Pela hesitação da fala em certos momentos, pode-se notar uma certa independência do tele-prompter, como se a fala fosse elaborada na hora.

\section{2 - Encontro noturno: O Programa do Jô}

O ambiente produzido pelo Programa do Jô (PJO) cria a cena de um ponto de encontro noturno em uma grande cidade. A imagem de São Paulo (local onde o programa é gravado) à noite, com a fotografia dos arranha-céus iluminados pelas luzes internas dos apartamentos preenche o fundo do programa num grande painel. Paralelamente a isso, imagens de outras cidades brasileiras de grande e médio porte, à noite, em seus locais turísticos, aparecem nas vinhetas entre os blocos do programa ratificando a idéia de que o PJO é um local onde as pessoas se encontram. Sobre um pequeno palco, encontra-se a mesa onde se posiciona o apresentador Jô Soares e, ao seu lado, um sofá onde ele recebe os convidados. À frente do Jô encontra-se a platéia que representa os interlocutores do apresentador e é o local onde o programa também pretende posicionar o telespectador: como parte integrante da cena. Assim, é com o Jô Soares que os telespectadores marcam seu "encontro noturno", criando a 
expectativa de que o programa televisivo cumpra o mesmo papel que uma saída casual deve ter: diversão, boa música, gente interessante.

A diversão é assegurada pelas piadas do Jô, que se mostra como uma companhia agradável, sofisticada e inteligente, que irá prover os acompanhantes com informação interessante e novidades do mundo artístico. A boa música é tocada pelo Sexteto do Jô, um grupo de músicos de meia idade que tocam preferencialmente jazz dando um tom de requinte e alta qualidade ao programa. O Sexteto fica posicionado também sobre o palco, à esquerda do vídeo, e recebe o comando de Jô Soares para que a música seja interrompida. As pessoas interessantes, além do próprio mediador, são representadas pelos convidados do programa que são agradavelmente apresentados à platéia e aos telespectadores por Jô Soares.

Apesar de ser gravado, o programa não sofre alteração em seu conteúdo, mantendo-o numa ilusão de ser ao vivo, como se o telespectador estivesse participando do encontro no momento em que o programa é exibido (após as vinte e três horas). Tudo isso visa reproduzir a cena da informalidade da saída à noite, na qual coisas inesperadas podem acontecer, os convidados não precisam estar tão bem articulados na sua fala e um certo improviso também é permitido. Nesse programa, como a cena sugere casualidade, a conversa procede da mesma maneira.

Mantendo uma média de dois convidados por programa, no dia 10/10/o6, Jô Soares recebeu a escritora Gisela Rao, que estava lançando o livro "Socorro Leitora - primeiro livro de auto-ajude-me", e a banda Quaternáglia, grupo de violonistas cujo estilo musical busca uma interface entre música erudita e popular. Esses dois convidados representam estratégias comunicativas diferenciadas utilizadas pelo programa. Segundo Mats Ekström (2000), o telejornalismo se apropria de pelo menos três estratégias comunicativas: a informação, as histórias de vida e as atrações. A informação pode ser conceituada pela característica do jornalismo de fornecer conhecimento sobre assuntos relevantes da atualidade (como vimos no BDB). Assim, a informação visa ensinar a audiência algo sobre o mundo para que ela possa orientar seu comportamento e sues papéis sociais (como trabalhadores, consumidores, vítimas, cidadãos). As histórias são estratégias narrativas usadas tanto para a construção das notícias (por meio de personagens, elementos dramáticos, construção de um clímax, efeitos visuais e sonoros) quanto por programas que usam 
a conversa no estúdio como estratégia. Neste caso, os programas contam com convidados que relatam suas história de vida dentro de uma narrativa mais ampla (relacionamentos amorosos, defesa do consumidor, casos de aborto, etc) e cumprem um papel previamente designado para eles pelos mediadores. A atração representa a característica do telejornalismo de abordar assuntos singulares e sensacionais como se fossem parte de um show. É o caso de assuntos que se anunciam como "não perca as imagens impressionantes do vulcão...” ou "não deixe de ver a entrevista exclusiva de ...”.

No PJO, podemos ver as três modalidades de comunicação, mas, durante a conversa, duas delas são mais evidentes: a informação ${ }^{9}$ - para os entrevistados que têm um caráter mais esclarecedor ou inusitado, como um dentista falando sobre mau hálito ou um biólogo divulgando algo desconhecido sobre insetos - e as histórias que são contadas pelos convidados. No dia em referência, os dois convidados representaram essas duas modalidades: o livro lançado por Gisela Rao serviu como gancho para uma conversa sobre relacionamentos amorosos embasados nas experiências fracassadas da autora sobre namoro e sexo, como podemos ver no exemplo abaixo.

Exemplo 3: sobre o relacionamento fracassado de Gisela Rao com um psicólogo.

\begin{abstract}
9 Desde 2005, o PJO também tem se dedicado a assuntos da esfera política, tanto nas entrevistas com representantes do campo, quanto com uma mesa redonda de debate com jornalistas que são apelidadas por ele como "meninas do Jô": Zileide Silva, Tereza Cruvinel, Lillian Witte Fibe, Ana Maria Tahan, Sonia Racy, Cristiana Lôbo, Lucia Hippólito e Maria Aparecida de Aquino. Com o propósito de analisar os casos de corrupção que envolveram o governo federal, o dia das meninas do Jô era para ser provisório, mas acabou angariando audiência e foi cobrado ao apresentador que deu a seguinte satisfação aos telespectadores: "eu quero lembrar novamente às pessoas que cobram ausência de comentários políticos neste momento. É evidente que eu também sinto uma falta louca. Já respondi alguns e-mails que perguntam: 'por que não tem aqueles comentários?'. Porque a lei eleitoral é praticamente uma camisa de força que vestem na gente. (...) Então, assim que acabe a vigência dessa lei draconiana, acaba na eleição agora, quando tiver a eleição do segundo turno, ou do returno, como dizem alguns, nós vamos voltar com esses temas com o mesmo vigor de antes e já, na própria segunda-feira, já vamos começar com uma nova rodada com a mesa das meninas do Jô (...)”.
\end{abstract}


Gisela: $\quad$ Aconteceram muitas coisas "leis de Murphy" nesse relacionamento...

Jô: $\quad$ Por exemplo? Conta, conta, eu quero ouvir.

Gisela: Por exemplo, na primeira semana eu já matei o gato dele (risos).

Jô: Culpa dele. Quem manda o filha-da-mãe ter gato. Matou por que?

Gisela: Porque eu fui indicar o nome do veterinário da minha gata...

Jô: $\quad$ Ah, você tem gata?

Gisela: Tenho, tenho.

Jô:

Como é o nome dela?

Gisela: Chama Bebezuda. Ou "bebê da mamãe" também.

Jô:

E o gato dele? Como é que chamava?

Gisela: $\quad O$ gato dele chamava Fi.

Jô: $\quad$ Fi?

Gisela: É porque ele ficava o dia inteiro "fi..fi..." (risos). Era chato pra caramba. Era pequenininho assim o gato...

Jô: $\quad$ Como é que ele ficava o dia inteiro?

Gisela: $\quad$ "fi...fi...fi..." (risos). Era insuportável, nunca vi um gato tão chato.

Jô: $\quad$ Assim, com essa vozinha fininha: "fi...fi.., vem cá, Fi? Vem cá Fi, Fi? Cala a boca" (risos). E aí o que você fez?

Gisela: Aí eu indiquei o meu veterinário para ele ir lá dar uma injeção no gato dele. Era um japonês seríssimo. Ele teve um choque anafilático e o gato caiu morto, duro, bateu as botas. O japonês, se fosse antigamente, teria feito arakiri. Ele ficou tão mal, ficou tão arrasado. Sabe essas coisas que só dá uma em um milhão? Deu no gato. O cara ficou uma semana em estado de ...

Jô: Que homem de sorte!

Gisela: Ficou uma semana em estado de choque. Tivemos que interromper o namoro uma semana.

Jô: $\quad$ Hum... eu cheguei a engasgar aqui com a água (risos). Quer dizer que...

Gisela: $\quad$... Muito sensível!

Jô: $\quad$ Sim, mas você não ficou dando apoio? Quer dizer que: "olha, segura essa barra aí, eu volto quando passar esse troço porque realmente o negócio do Fi é problema seu, é filho...O Fi para mim fo..." (risos)

Gisela: Mas...mas ele achou que tinha que ter um período de luto. Porque para mim, eu já estava com outro gato lá na casa dele no dia seguinte, né?

Jô: $\quad$ Claro.

Gisela: $\quad$ Porque a gente é rápida, né? Mas ele falou: "não, preciso ficar sozinho por uma semana". Eu falei: "legal".

Jô: $\quad$ Será que foi ele que matou o gato para se livrar de você?

Gisela: (risos) Mas ele voltou uma semana depois. "Já estou bem, a gente já pode continuar o namoro".

O grupo Quaternáglia, entretanto, corresponde à modalidade de informação pois as perguntas de Jô foram direcionadas a um conhecimento mais amplo sobre a banda.

Exemplo 4: sobre a formação do grupo musical. 
Jô:

Quaternáglia:

Com é que vocês se encontraram? Há dezessete anos isso...

Jô:

Catorze

Quaternáglia: Olha, nós... eu e o Fábio estudávamos com o mesmo professor e um amigo que não está mais hoje, o Eduardo Fleuri, e o Breno Chaves, que não fazem mais parte da formação, mas no início nos ajudaram a ter essa idéia. E nós começamos como quatro amigos...

Jô: $\quad$ No Rio?

Quaternáglia: Em São Paulo.

Jô: $\quad$ Vocês quatro são de São Paulo?

Quaternáglia: O Fernando é mineiro, mas num é? (reproduzindo o sotaque mineiro)

Jô: $\quad$ É mineiro, quietinho. Mineirinho come quieto.

Quaternáglia: Fizemos...ah... na verdade, começamos como quatro amigos querendo fazer música juntos, né. Bom, o trabalho foi ganhando força, foi crescendo. Nós não tínhamos nenhuma, nenhuma ambição específica com ele e eu acho que é por isso que dá certo.

Jô: Vocês... os violões são absolutamente idênticos ou tem alguma diferença entre cada um deles? Um de oito cordas, aquelas coisas, ou não?

Quaternáglia: Tem um de sete cordas que é este meu.

Jô Soares mostra-se no programa como alguém que entende um pouco de todos os assuntos dizendo com freqüência que já leu algo sobre o que o entrevistado está falando, ou que conhece alguém em comum com ele. Entretanto, isso não assume um tom professoral, mas funciona como uma estratégia de tornar a conversa mais interessante e autorizá-lo a fazer aquelas entrevistas. O apresentador procura intercalar sua fala com a do entrevistado, mas o interrompe quando precisa esclarecer melhor alguma coisa, ou fazer brincadeiras com o entrevistado. Apesar de as perguntas estarem num roteiro, as falas são ditas com um certo improviso e há flexibilidade para fazer comentários sobre o que o entrevistado disse. Por isso, o programa insinua espontaneidade.

\section{3 - Troca de idéias na Saia Justa}

A saia justa, vestimenta feminina que adere perfeitamente ao corpo pela "justeza", caiu na linguagem popular para designar "situações de aperto", circunstâncias em que alguém se vê confinado, constrangido, precisando se livrar de algo ou alguém. Baseado nisso, o programa Saia Justa (SJ) busca reproduzir esse duplo sentido da expressão "saia justa": a feminilidade de suas integrantes e a situação difícil de temas gerais que não têm resposta fácil, e portanto, não devem levar a um sentido comum. 
O programa traz cinco mulheres como protagonistas: a jornalista Mônica Waldvogel, a cantora Ana Carolina ${ }^{10}$, a atriz Maitê Proença, a ex-modelo e também atriz Betty Lago e a filósofa Márcia Tiburi. Num cenário composto por grandes sofás posicionados num quadrado, as protagonistas se colocam uma de frente para a outra. Atrás delas, pode-se ver, apoiados sobre uma plataforma de madeira, luminárias, canecas, pequenos adereços como estátuas, vasos e objetos representativos da área de atuação delas: um violão, roupas e acessórios, porta-retratos, revistas e livros. Esse ambiente é cercado por um fundo que remete às cores e o logotipo do programa: bege, laranja e branco, tudo em tons claros.

Ao longo do programa, as participantes debatem sobre o tema proposto para o dia mudando a forma de argumentação permanentemente: ora elas dão aulas umas às outras, ora contam suas histórias. $\mathrm{O}$ uso dos argumentos coloca pontos de vista divergentes sobre um assunto levando o telespectador a pensar sob um olhar diferenciado, o que ilumina as questões abordadas. O programa transmite a idéia de que é uma conversa permanente sobre os assuntos: na abertura da edição do dia 18/10/o6, o SJ mostrou um suposto flagra de uma conversa entre Márcia Tiburi e Ana Carolina e na passagem dos blocos as participantes continuavam falando, enquanto as luzes do estúdio diminuíam de intensidade e o programa era então interrompido. O mesmo ocorre na volta do intervalo comercial. Como a palavra é franqueada, muitas vezes ocorre a sobreposição das falas, o que causa a impressão de ser um debate de idéias entre cinco amigas que marcaram para conversar, como a chamada do programa sugere: "sábado à noite, nada melhor do que sentar com as amigas para botar a conversa em dia”. O SJ rompe com os padrões midiáticos quando ocorre a sobreposição e a câmera não consegue acompanhar a dinâmica da troca, deixando muitas vezes o telespectador sem saber quem fez alguma pergunta ou comentário.

\footnotetext{
10 No final de 2006, Ana Carolina saiu do programa e foi substituída por Sônia Francine, a Soninha, apresentadora de esportes da ESPN Brasil. Neste artigo, continuaremos a nos referir a Ana Carolina como integrante do programa.
} 
Exemplo 5: Na abertura do primeiro bloco do programa do dia 18/10/06, Mônica Waldvogel introduziu o assunto que levou ao início da conversação.

\section{Mônica Waldvogel}

(inicialmente olhando para a câmera para interpelar o telespectador e, depois, dirigindo-se às suas colegas)

\section{Ana Carolina Mônica Waldvogel Ana Carolina}

?

\section{Ana Carolina}

\section{Betty Lago \\ Ana Carolina \\ Betty Lago \\ Mônica Waldvogel Ana Carolina}

\section{Betty Lago}

Mônica Waldvogel Márcia Tiburi Ana Carolina Betty Lago

\section{Maitê Proença \\ Betty Lago \\ Márcia Tiburi}

\section{Mônica Waldvogel Márcia Tiburi}

\section{Maitê Proença:}

Mônica Waldvogel:
Olá! Num mundo em que já está tudo tão dominado, o Saia Justa pergunta: o que é ser rebelde? Aliás, como é que a gente identifica um rebelde? E o movimento de rebeldia, alguém já viu por aí? Como é que é ser rebelde no século XXI, no mundo Ocidental, nesse que a gente vive: tudo sério, tudo certinho, tudo já está previsto, tudo já está encaixado, tudo já tem um nicho onde você encaixa...

Tudo já aconteceu, né?

Tudo já aconteceu.

E começou... Bem, na década de cinqüenta era o James Dean, jaqueta de couro, calça jeans. Depois foi a Tropicália...

Hippies.

Movimento punk, movimento hippie. Rebeldes, rebeldes, rebeldes. E hoje...

LSD. Queimaram muito sutiã. Isso era bom.

É, o pessoal enlouqueceu bem.

$\mathrm{O}$ pessoal enlouqueceu bem.

Quando pode tudo, o que é se rebelar?

A rebeldia, é... ela se adequou um pouco às normas capitalistas. Quer dizer, você vê roupa de marca com a cara do Che Guevara (risos). Entendeu? Tatuagem, piercing tem em qualquer esquina. Famílias, vão pais... entendeu? Rebeldia...

Você falou uma coisa muito importante: as roupas mais anárquicas são dos japoneses e são as mais caras do mundo.

Carésimas!

Anárquicas como?

Calça rasgada você compra...

Assim, rasgadas, com buracos, é... suéteres que só têm uma manga.

(Sobreposição)

Larga, sem forma...

É, não segue um padrão.

O que vocês estão falando é contra a rebeldia. Porque a rebeldia é algo, um movimento que acontece em qualquer tempo quando esse tempo consegue produzir um descontentamento ativo. Então é claro que hoje em dia quem se vestir com calça rasgada que dá para comprar, enfim... é produto do capitalismo...

Está contentíssimo.

Está contentíssimo. Então, qualquer um que faça alguma coisa que seria rebeldia no passado...

(...)

A Mônica Waldvogel, essa pessoa sensata, centrada, deve ter tido um momento de rebeldia. Como foi?

$\mathrm{Eu}$ fui muito rebelde porque eu era de uma família muito, muito... uma menina muito guardada, de família, assim, com pais vigilantes, que não deixavam fazer nada, moralmente muito rigorosos e que tiveram conflito em compreender o que aconteceu nos anos sessenta com o comportamento. E aí, eu sou a filha mais velha, e quando eu cheguei, eu fui levando todas as pancadas porque toda vez que eu fazia alguma coisa, eu recebia um "não" que vinha dos pais deles, né. Então, desde aderir aos 
conflitos de esquerda, aos protestos contra a ditadura, até ficar grávida na adolescência, digamos que naquele momento isso era ser rebelde mesmo. Usar saião hippie com sandália da feira, a bolsa de couro cru, quer dizer, eu era um clichê rebelde naquele tempo, nos anos setenta.

Ao passo que há uma idéia de igualdade de status entre as participantes do programa (o que caracterizaria uma conversa entre amigas), há também a interpretação de um papel na cena. Márcia Tiburi, no trecho exemplificado, usa o tom professoral como estratégia argumentativa. É ela quem dá as aulas sobre ser rebelde, enquanto o exemplo de rebeldia é dado por meio da biografia de Mônica Waldvogel. Deste modo, os argumentos se modificam o tempo todo no programa de acordo com a opinião de cada participante. Por isso, o programa congregou mulheres com diferentes formações e experiências de vida para dar um caráter de contradição e conflito ao debate, que é seu principal atrativo, apesar de tudo ser feito com muito bom humor. É possível perceber, porém, um lugar de fala diferenciado para Mônica Waldvogel, não como se ela fosse a detentora da "verdade absoluta" (a verdade fica a cargo de cada telespectador), mas na condução do programa, na introdução dos temas e em colocar ordem quando a discussão se torna demasiadamente confusa.

\section{Considerações finais:}

A análise do Bom Dia Brasil, Programa do Jô e Saia Justa revelou que a forma de apropriação da conversação depende da proposta que o programa pretende firmar com sua audiência. Assim, a temática - que dá o tom de formalidade ou informalidade -, a cena reproduzida pelo cenário, o papel dos participantes da conversa e sua performance são específicos dos programas. Por outro lado, também encontramos elementos comuns sobre a conversação no telejornalismo que pretendemos elucidar agora.

Em primeiro lugar, apesar de a performance dos participantes ser diferenciada, há sempre alguém que centraliza a autoridade para controlar a emissão do programa e, conseqüentemente, dar o rumo da conversa. Este "centralizador" que pode ser um ou mais - é quem dá o ritmo à conversação, estabelece o foco temático e indica os turnos de fala. Essa postura carrega em si o princípio do telejornalismo de clareza da informação, para que o telespectador possa acompanhar 
o que está sendo relatado. Por isso, de forma geral, é um jornalista ou alguém reconhecido dentro do campo que desempenha essa função. Isso fica evidente no SJ que conta com participantes conhecidas do público, mas quem ordena o programa é a jornalista Mônica Valdvogel. No caso do PJO, a credibilidade do apresentador decorre do fato de ele ser reconhecido pela audiência pelas entrevistas que faz há 18 anos, como fica claro em sua fala: "numa pesquisa da CBN, eu saí como a pessoa de maior credibilidade (...). Dezoito anos de entrevistas, nunca houve uma entrevista aqui que tenha sido paga" (edição de 10/10/06). No BDB, todos os participantes da conversa são jornalistas.

Em segundo lugar, percebe-se que as conversas televisivas são marcadas por uma temporalidade definida. A rigidez da grade de programação e a dependência dos blocos publicitários impedem que as conversas se alonguem por tempo indefinido e acabam forçando os apresentadores a cortar a fala dos entrevistados quando eles se alongam demais ou quando perdem o foco. O SJ é o único que procura burlar o fato de que as conversas possuem um tempo determinado deixando que as protagonistas continuem falando enquanto entra o comercial. Isso dá uma impressão de continuidade à conversa, mas sempre precisa ser retomada ao voltar do intervalo.

Por fim, é visível que nas conversas telejornalísticas há uma preparação prévia por parte dos participantes para a abordagem dos assuntos. No $\mathrm{BDB}$, o teleprompter guia a fala dos apresentadores e dos especialistas (o que fica claro com o olhar permanente para a câmera), indica o momento em que alguém pode inserir algum comentário rápido sobre o assunto que fora tratado. Além disso, os apresentadores possuem um roteiro com perguntas e comentários a fazer para os especialistas, deixando que a fala seja elaborada na hora (o que fica claro com o gaguejar e os erros dos apresentadores), mas ainda assim ela é previamente pensada. No PJO, o apresentador segura cartelas e olha para elas para formular algumas perguntas. Esse "script" serve de direcionamento para a entrevista, porém não a limita, deixando o apresentador livre para fazer intervenções, esclarecimentos e piadas quando acha pertinente. No SJ, pode-se ver que as participantes possuem também um roteiro com pesquisas que elas mesmas fizeram sobre os temas que serão abordados na edição do dia. 
A figura do "centralizador" da conversa, a delimitação temporal e a preparação prévia podem ser pensados como aspectos gerais da conversação no telejornalismo. Outros programas que utilizam a conversação como forma de transmissão da informação e construção do seu estilo podem confirmar essas e revelar outras características sobre a conversação no telejornalismo.

\section{Referências:}

ALBUQUERQUE, Afonso de. Um outro quarto poder. Imprensa e compromisso político no Brasil In Revista Fronteiras - estudos midiáticos, vol. 1, dezembro de 1999.

BAKHTIN, Mikhail. Estética da criação verbal. Trad. Maria Ermantina Galvão Gomes; revisão Marina Appenzeller. São Paulo: Martins Fontes, 1992. coleção ensino superior.

BARBERO, Jesus-Martin. Dos meios às mediações. Comunicação, cultura e hegemonia. Rio de janeiro, UFRJ, 1997.

BRAGA, José Luiz. Roda Vida - uma encenação da esfera pública. Texto apresentado no Encontro Anual de Núcleos de Pesquisa da Intercom, PJO - Núcleo de Jornalismo. 4-9 de setembro de 2006, Brasília, DF.

BRAGA, José Luiz. Sobre a conversação. In: FAUSTO NETO, Antonio, Sérgio Dayrell porto e José Luiz Braga (orgs.) Brasil - Comunicação, Cultura e Política. Rio de Janeiro: Diadorim, 1994, p. 289-308.

BURKE, Peter. A arte da conversação. (trad. Álvaro Luiz Hattnher). São Paulo: Editora da Universidade Estadual Paulista, 1995.

CHALABY, Jean. O jornalismo como invenção anglo-americana. Comparação entre o desenvolvimento do jornalismo francês e anglo-americano (1830-1920). In: Media \& Jornalismo, Vol. $1, \mathrm{n}^{\circ} 3$, 2003, 29-50. capturado em http://revcom.portcom.intercom.org.br/scielo.php?script=sci arttex\&pid=S1645$56812003000300004 \& I n g=p t \& n r m=$ iso \&tlng $=$ pt. Artigo originalmente publicado no European Journal of Communication, Vol. II, $\mathrm{n}^{\circ}{ }_{3}, 1996$.

DUARTE, Elizabeth Bastos. Televisão: ensaios metodológicos. Porto Alegre: Sulina, 2004.

EKSTRÖM, Mats. Informatio, storytelling and attractions: TV journalism in three modes of communication. In: Media, Culture \& Society, 2000, Vol. 22, 465-492.

GOFFMAN, Erving. A Representação do Eu na Vida Cotidiana (trad. Maria Célia Santos Raposo). Petrópolis: Vozes, 2005.

GOMES, Itania. A noção de gênero televisivo como estratégia de interação: o diálogo entre os cultural studies e os estudos da linguagem", in Revista Fronteiras, São Leopoldo, Programa de Pós Graduação em Comunicação da UNISINOs, dezembro de 2002. 
GOMES, Wilson. Jornalismo e esfera civil. O interesse público como princípio moral do jornalismo. In: PERUZZO, Cicília (org). Comunicação para a Cidadania. Salvador/ São Paulo, UNEB, INTERCOM, 2003, p. 28-51.

GUERRA, Josenildo Luiz. O percurso interpretativo na produção da notícia, Salvador/UFBA, 2003 (Tese de doutorado apresentada ao Programa de PósGraduação em Comunicação e Cultura Contemporâneas);

JOST, François. "Le Journal Télévisé” in Introduction à l'analyse de la television, $2^{\mathrm{a}}$, Ellipses Édition Marketing, 2004a, 75-102.

JOST, François. Seis Lições sobre Televisão. Porto Alegra: Sulina, 2004b.

LIVINGSTONE, Sonia M.; LUNT, Peter. Talk on Television: audience participation and public debate. London and New York: Routledge, 1994.

MARCUSCHI, Luiz Antônio. Análise da Conversação.São Paulo: Ática, 1998, 94p.

MILLER, Stephen. Conversation - a history of a declining art. New York: Vail-Ballou Press, 2006.

ORNEBRING, Henrik. Televising the Public Sphere. Forty years of current affairs debate programmes on Swedish television, in European Journal of Communication Vol 18 (4), 2003, 501-527;

PEREIRA, Cárlida Emerim Jacinto. Das entrevistas. In: Produção televisiva: as diferentes funções estratégicas da entrevista na configuração discursiva da notícia. Tese de doutorado defendida pela UNISINOS, 2004.

REZENDE, Guilherme Jorge de. Telejornalismo no Brasil. Um perfil editorial, SP, Summus Editorial, 2000;

SCHUDSON, Michael. Discovering the news: a social history of American Newspaper. USA: Basic Book, 1978.

SEATON, Jean. Broadcasting history. in: CURRAN, James \& SEANTON, Jean. Power without responsability. The press, broadcasting and new media in Britain, 6a ed., London/ New York, Routledge, 2003, 107-234.

TARDE, Gabriel. A opinião e a conversação. In: A opinião e as massas. São Paulo: Martins Fontes, 1992, pp. 79-154.

TRAQUINA, Nelson. Teorias do jornalismo, porque as notícias são como são. Florianópolis: Insular, vol. 1, 2004, 224p.

TRAQUINA, Nelson. Teorias do jornalismo. A tribo jornalística - uma comunidade interpretativa transnacional. Florianópolis: Insular, 2005, 216p.

WILLIAMS, Raymond. Gêneros. In: Marxismo e Literatura. Trad. Waltensir Dutra. Rio de Janeiro: Zahar Editores, 1971, pp. 179-184.

WILLIAMS, Raymond. The tecnology and the society. In: Television. Technology and cultural form, 2a, London: Routledge, 1997, pp. 9-31.

WOLF, Mauro. Sociologia de la vida cotidiana. Madri: Cátedra, 1994. 